\title{
PREDICTION OF SOME CARCASS COMPONENTS OF FATTENED BARKI LAMBS USING PRINCIPAL COMPONENTS TECHNIQUES
}

\author{
S. M. Alsheikh, A. H. Hammam and M. M. Mokhtar \\ Department of Animal Breeding, Desert Research Center, P. O. Box 11753, \\ Mataria, Cairo, Egypt
}

\section{SUMMARY}

The present study examined the use of principal components techniques for some live body measurements to predict some carcass components of fattened Barki male lambs. The study was carried out during 1997 at Borg El-Arab Experimental Station, which belongs to the Agricultural Research Center, Ministry of Agriculture and is located some $40 \mathrm{~km}$ west of Alexandria, Egypt. Fifty Barki male lambs with an average initial live body weight of $26 \mathrm{~kg}$ were included in the study. Eight linear live body measurements were taken before slaughtering. Carcass traits were carcass weight (CWT), total weight of the prime cuts (TPC), total weight of secondary cuts (TSC), percentages of prime cuts and secondary cuts TPC and TSC as a percentage from CWT (PCP and SCP) and logs of TPC and TSC (LogP and LogS). Principal components $(P C)$ techniques were used to summarize the variations between different eight live body measurements into one measurement called body size (BZ). BZ was calculated by multiplying the elements of the first eigenvector of the first PC by each body measurement. Simple regression analysis of different carcass traits on BZ was done. The eight studied variables used presented significant statistical correlation ( $p$ $<0.05$ ) and the first two PC's of them explained $70 \%$ of the total variance. The regression coefficients of CWT, TPC, TSC, PCP, SCP, LogP and LogS were $0.11 \mathrm{~kg}$, $0.06 \mathrm{~kg}, 0.05 \mathrm{~kg},-0.005 \%, 0.06 \%,-0.00005 \mathrm{Log}$ and $0.0007 \mathrm{Log}$, respectively. It could be concluded that, principal components techniques summarized the variation in body measurements into two principal components that accounted for $70 \%$ of variation in the dependency structure. The first principal component provided a measure of the general body size. The increases of TPC and TSC contributed 55\% $(60 \mathrm{~g})$ and $45 \%(50 \mathrm{~g})$, respectively, to the increase of CWT $(110 \mathrm{~g})$. The regression coefficients of the TPC and TSC after transformed data to $\log _{10}$ were almost zero.

Keywords: Barki lambs, regression, prime cuts, second cuts

\section{INTRODUCTION}

Barki is one of the three major sheep breeds of Egypt. About one million heads of this breed are maintained along the North Western Coastal Area (NWCA) (MOALR, 2004), out of which 300-350 thousand weaned male lambs may be produced yearly. The breed is characterized by small body size and good adaptation to the arid and semi-arid conditions prevailing in that area. Productivity of such animals is rather

Issued by The Egyptian Society of Animal Production 
low, but this may constitute a part of the ecological balance for the ecosystem. Flock owners tend to get rid of lambs soon after weaning at 3-4 months usually with the advent of the dry season. If these male lambs were properly fattened, they would be expected to produce an extra 6000 tons of lambs/year with better carcass quality (Younis, 1998).

Principal components analysis is a technique used to summarize most of the variation in a multivariate system in fewer variables. In practice, one usually knows from earlier studies, the nature of the data, or even the pattern of components which of these variables have large and distinct variance that could be extracted from variation system. The number of components might be computed until some arbitrarily large proportion ( $75 \%$ or more) of the variance has been explained. If that proportion cannot be explained by the first 4 or 5 components, it is usually fruitless to continue extracting more vectors. In this case, the characteristics of the latter components, may be difficult, if not impossible, to interpret (Morrison, 1976). The present study examined the use of principal components technique for some live body measurements to predict some carcass components of fattened Barki male lambs.

\section{MATERIALS AND METHODS}

\section{Lambs and feeding groups}

The present study was carried out at Borg El-Arab Experimental Station, which belongs to the Agricultural Research Center and is located some $40 \mathrm{~km}$ west of Alexandria, during 1997, as a part of a project which was financially supported by the National Councils, Agriculture Research Center. Fifty Barki male lambs with an average live body weight and age of $26 \mathrm{~kg}$ and 180 days, respectively, were included in this study. Lambs were equally divided at random into five feeding groups as follows.

1. Barley grains + grazing natural pasture $(8 \mathrm{hr} /$ day) $(\mathrm{G} 1)$.

2. Barley grains + barseem hay ad libtum $(\mathrm{G} 2)$

3. Concentrate feed mixture $14 \%$ protein + barseem hay ad libtum (G3).

4. Barley grains + concentrate feed mixture $14 \%$ protein + molasses + Acacia Saligna ad libtum (G4).

5. Barley grains + concentrate feed mixture $14 \%$ protein + molasses + Acacia Saligna irrigated with untreated sewage water during cultivated period ad libtum (G5).

Fresh water was available twice daily for all experimental groups. Also, salt blocks were available to all animals. When the lambs reached $45 \mathrm{~kg}$ average live body weight, they were fasted overnight and weighed then slaughtered.

\section{Body measurements}

Live linear body measurements were taken before slaughtering using a plastic measuring tape and included:

1. Body length, front of shoulder to hook bones (BL).

2. Heart girth, circumference of chest (HG).

3. Height at withers (HW).

4. Height at shoulder (HS).

5. Tail length (TL). 
6. Tail upper circumference, at the point of attachment with the body (TU).

7. Tail middle circumference, at the thickest portion of the tail (TM).

8. Tail thickness, at the thickest portion of the tail (measured by caliper) (TT).

Younis et al. (1999), who used the same data, found no significant $(\mathrm{P}<0.05)$ differences among the 5 groups in body measurements, so, in all the following statistical analyses the 50 lambs were used as one group.

\section{Carcass components}

Carcass traits recorded for each animal were carcass weight (CWT), total weight of the prime cuts (TPC), total weight of secondary cuts (TSC). In addition, TPC and TSC as a percentage of CWT (PCP and SCP) and $\log _{10}$ TPC and $\log _{10}$ TSC (LogP and $\log S$ ) were calculated.

\section{Principal components (PC) analysis}

PC analysis was used to summarize the variation in different live body measurements into one measurement called body size (BZ). PC analysis was done through the JMP procedure (SAS, 1998). The first principal component $\left(\mathrm{PC}_{1}\right)$ of the observations study variables $(\mathrm{X})$ is linear component. $\mathrm{PC}_{1}$ was used to calculate $\mathrm{BZ}$ by multiplying the elements of the first eigenvector times each body measurement as follows:

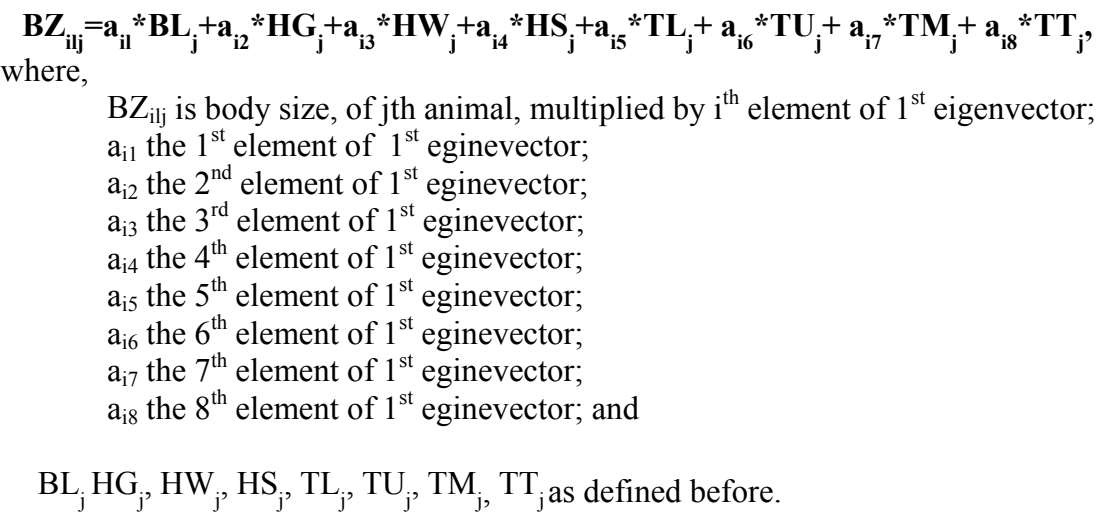

\section{RESULTS AND DISCUSSIONS}

\section{Principal components (PC)}

Table 1 shows that there were significant $(\mathrm{P}<0.05)$ correlation coefficients between the 8 study variables. Also, table 2 shows that the first PC of the 8 study variables explains $50 \%$ of the total variance of the body size while the first two PC's explain $70 \%$ of the total variance. These coefficients were higher than $34.7 \%$ and $54.2 \%$ for $1^{\text {st }}$ PC and for the first two PC's, respectively, obtained by Santos and Barros (2004) who used the PC technique to summarize ten variables. The $1^{\text {st }} \mathrm{PC}$ accounted for variability less than $60 \%$ reported by El-Sheikh et al. (2000), who used 
PC technique to summarize five variables. These results indicate that the 8 study variables were suitable to characterize the body size of fattened Barki male lambs.

Table 1. Correlation coefficients matrix between the eight studied variables

\begin{tabular}{lcccccccr}
\hline Variables & BL & HG & HW & HS & TL & TU & TM & TT \\
\hline HG & 0.36 & & & & & & & \\
HW & 0.50 & 0.73 & & & & & & \\
HS & 0.45 & 0.41 & 0.69 & & & & & \\
TL & 0.41 & 0.52 & 0.50 & 0.39 & & & & \\
TU & 0.43 & 0.70 & 0.35 & 0.41 & 0.47 & & & \\
TM & 0.32 & 0.58 & 0.71 & 0.60 & 0.34 & 0.85 & & \\
TT & 0.32 & 0.50 & 0.53 & 0.36 & 0.57 & 0.53 & 0.50 & \\
\hline
\end{tabular}

$\mathrm{BL}=$ Body length, $\mathrm{HG}=$ Heart girth, $\mathrm{HW}=$ Height at withers, $\mathrm{HS}=$ Height at shoulder, $\mathrm{TL}=$ Tail length, $\mathrm{TU}=$ Tail upper circumference, $\mathrm{TM}=$ Tail middle circumference, $\mathrm{TT}=$ Tail thickness.

Table 2. Principal components relative importance in the verified variance justification

\begin{tabular}{lcccccccc}
\hline Items & \multicolumn{8}{c}{ Principal component } \\
\cline { 2 - 9 } & $\mathbf{1}$ & $\mathbf{2}$ & $\mathbf{3}$ & $\mathbf{4}$ & $\mathbf{5}$ & $\mathbf{6}$ & $\mathbf{7}$ & $\mathbf{8}$ \\
\hline Variance (V) & 3.95 & 1.62 & 0.89 & 0.48 & 0.38 & 0.31 & 0.26 & 0.10 \\
V explained (\%) & 50 & 20 & 11 & 6 & 5 & 4 & 3 & 1 \\
Accumulated (\%) & 50 & 70 & 81 & 87 & 92 & 96 & 99 & 100 \\
\hline
\end{tabular}

The values of the last two rows were rounded to the nearest integer.

Table 3 shows the first two PC factor coefficients. The coefficients of the $1^{\text {st }} \mathrm{PC}$ were used to calculate the BZ. Figure 1 shows graphical projection of the selected eight variables on the $1^{\text {st }}$ and $2^{\text {nd }} \mathrm{PC}$ axis. All study variables were nearest to the two axes and to the origin point $(0,0)$. In this case, variables play higher importance relevance in the variance justification (Blasco, 1996).

Table 3. Principal component (PC) factor coefficients

\begin{tabular}{lllllllll}
\hline PC & BL & HG & HW & HS & TL & TU & TM & TT \\
\hline $1^{\text {st }} \mathrm{PC}$ & 0.58 & 0.77 & 0.71 & 0.50 & 0.71 & 0.82 & 0.69 & 0.79 \\
$2^{\text {nd }} \mathrm{PC}$ & 0.29 & -0.30 & 0.56 & 0.76 & 0.08 & -0.44 & -0.60 & 0.01 \\
\hline BL = Body length, HG = Heart girth, HW = Height at withers, HS = Height at shoulder, \\
TL = Tail length, TU = Tail upper circumference, TM = Tail Middle circumference, TT = Tail \\
Thickness.
\end{tabular}

\section{Carcass components}

Figure 2 shows the regression lines of CWT, TPC and TSC in $\mathrm{kg}$ on the PC of BZ of fattened Barki lambs. The regressions lines of all these traits were linearly $(\mathrm{P}<0.05)$ positive. The regression coefficients of CWT, TPC and TSC were 0.11, 0.06 and $0.05 \mathrm{~kg}$, respectively, i.e. when the $\mathrm{BZ}$ of the fattened Barki male lambs increased by one unit CWT increased only by $110 \mathrm{~g}$ and this increase was divided into $60 \mathrm{~g}(55 \%)$ and $50 \mathrm{~g}(45 \%)$ for TPC and TSC, respectively. 


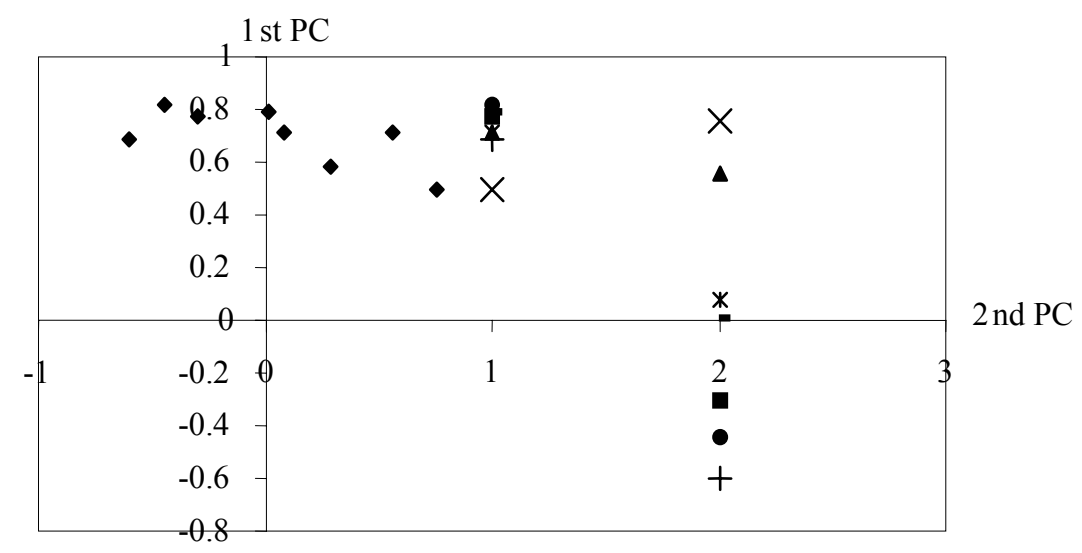

Figure 1. Graphical projection of eight studied variables on the $1^{\text {st }}$ and $2^{\text {nd }}$ principal component axis

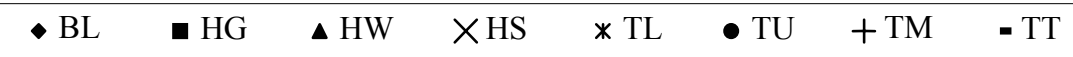

$\mathrm{BL}=$ Body length, $\mathrm{HG}=$ Heart girth, $\mathrm{HW}=$ Height at withers, $\mathrm{HS}=$ Height at shoulder, $\mathrm{TL}=$ Tail length, $\mathrm{TU}=$ Tail upper circumference, $\mathrm{TM}=$ Tail Middle circumference, $\mathrm{TT}=$ Tail Thickness.

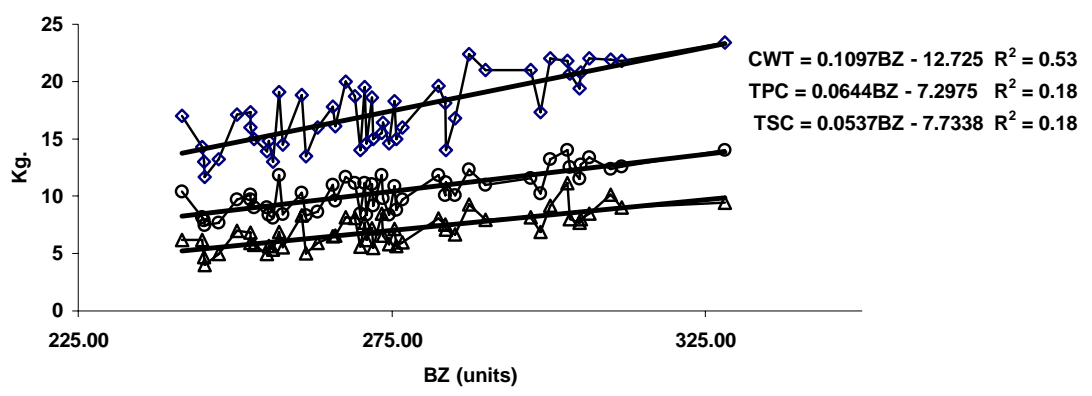

$\multimap$ CWT $\multimap$ TPC $\triangle$ TSC Linear (CWT) Linear (TPC) - Linear (TSC)

Figure 2. Regression of carcass weight in kg. (CWT), total weight of prime cuts in $\mathrm{kg}$ (TPC) and total weight of secondary cuts in $\mathrm{kg}$. (TSC) on principal component of body size (BZ) of fattened Barki lambs 
The regression line of PCP, SCP, $\log \mathrm{P}$ and $\operatorname{LogS}$ on the principal component of $\mathrm{BZ}$ of fattened Barki lambs are shown in Figures 3 and 4, respectively. The regression coefficients of $\mathrm{PCP}, \mathrm{SCP}, \log \mathrm{P}$ and $\operatorname{LogS}$ were $-0.005 \%, 0.06 \%$, $0.00005 \mathrm{log}$ and $0.0007 \mathrm{log}$, respectively. These regression coefficients were almost zero. This indicated that the increases of TPC and TSC weights were not absolutely linear.

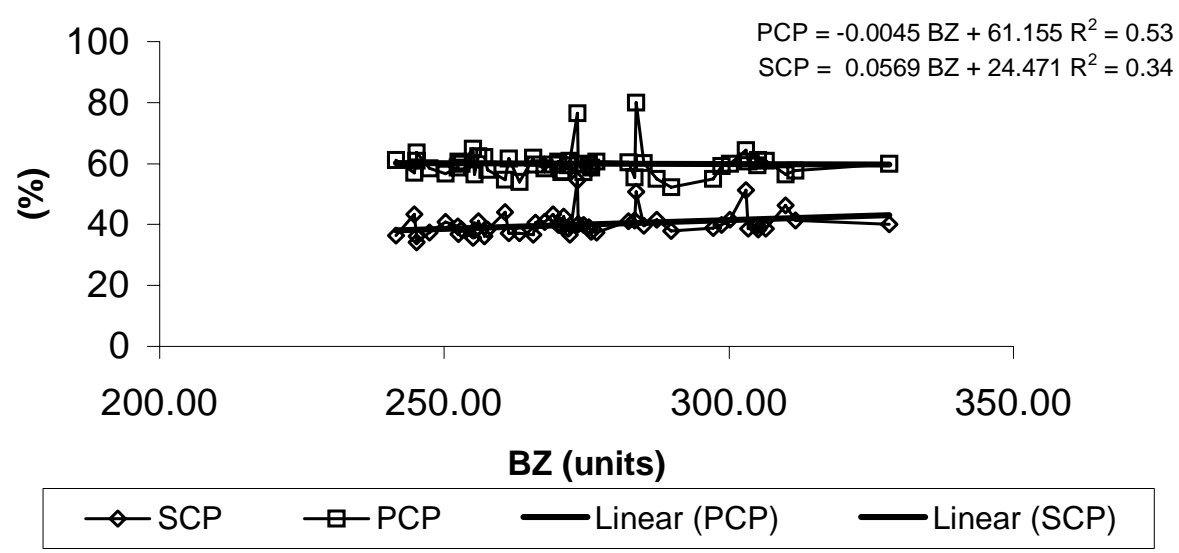

Figure 3. Regression of prime cuts (PCP) and secondary cuts (TSC) percentages on principal component of body size (BZ) of fattened Barki lambs

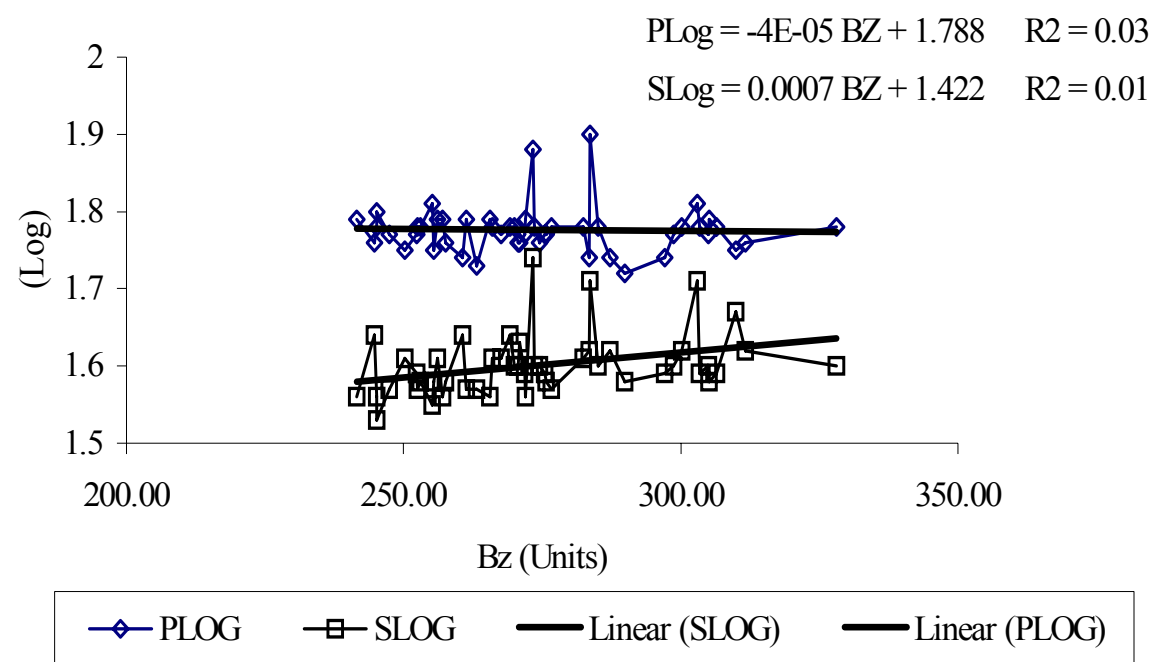

Figure 4. Regression of $\log _{10}$ of prime cuts (LogP) and secondary cuts (LogS) on principal component of body size (BZ) of fattened Barki lambs 


\section{CONCLUSIONS}

It could be concluded that, principal components technique could summarize the variation in body measurements into two principal components that accounted for $70 \%$ of variation in the dependency structure. The first principal component provided a measure of the general body size.

\section{REFERENCES}

Blasco, A., 1996. Analysis de datos experimentales para proyectos fin de carrea. Servicio de Publicaciones, Departamento de Ciencia Animal, Valência, 91 p.

El-Sheikh, S.M., E. A. El-Tawil and O. Salama, 2000. Among breed variation in tail size in sheep. Proc. $3^{\text {rd }}$ all Africa Conf. Anim. Agric. \& $11^{\text {th }}$ Conf. Egyptian Soc. Anim. Prod., Alexandria, Egypt, 6-9 November 2000: 101-108.

MOLAR, 2004. Agricultural Statistics, Economic Affairs Sector. Ministry of Agriculture and Land Reclamation, Egypt. pp 233.

Morrison, D.F., 1976. Multivariate Statistical Methods (2 ${ }^{\text {nd }}$ Ed). McGrow-Hill Book Compony. N. Y. St. Louis San Francisco Auckland Dusseldorf Johannesburg, pp 210.

Santos, J.C.R. and E.V. Barros, 2004. The principal components analysis as a tool for a better management of bovines farming system. $55^{\text {th }}$ EAAP meeting, Bled, $5^{\text {th }}$ $9^{\text {th }}$ September 2004, (Abstract).

SAS, 1998. User's guide. 6.12 edn, Statistical Analysis Systems Institute Inc. Cary NC 27511-8000, USA.

Younis, A.A., 1998. Small ruminant production systems in Egypt. Egyptian J. Anim. Prod. Suppl. Issue, 35: 128-144.

Younis, A. A., A.M.M. Salem, M.TH. Hassan and M.M. Mokhtar, 1999. The use of acacia, hay and natural grazing as roughages in fattening rations for desert Barki lambs. Workshop on Livestock and Drought: Policies for Coping with changes. Cairo, 24-27 May 1999: 81-87. 


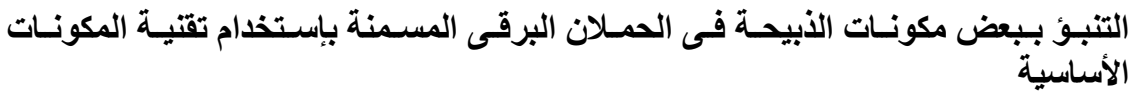

سمير محمد الثيخ، أحمد حسين همام، مرفت محمود مختار

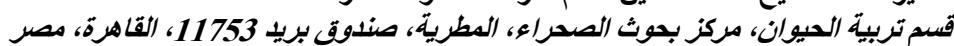

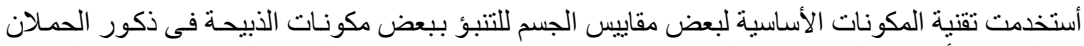

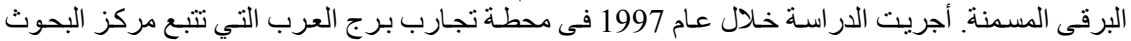

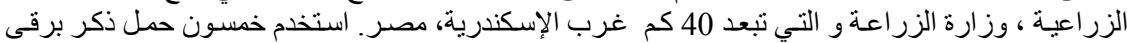

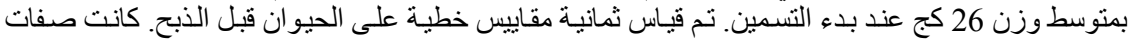

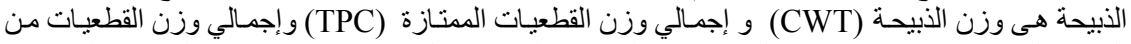

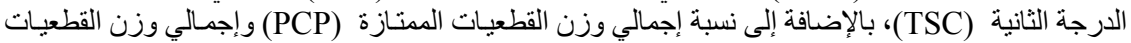

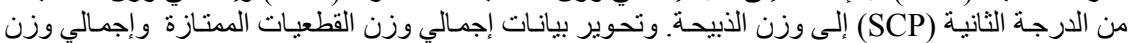

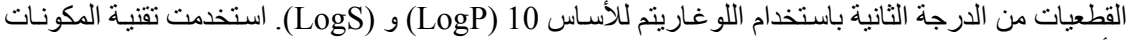

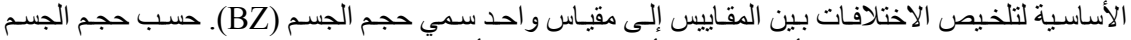

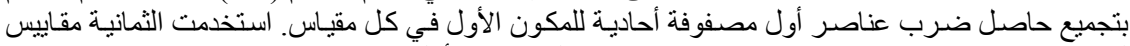

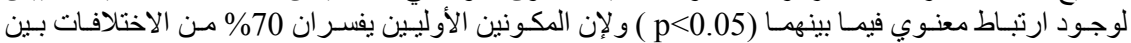

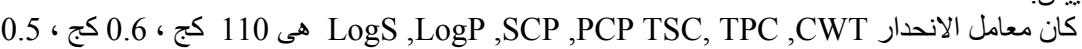

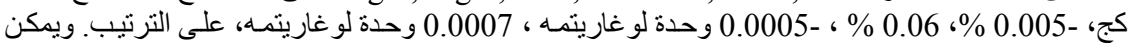

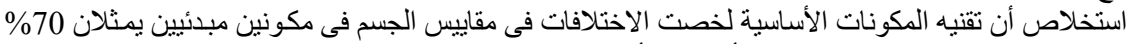

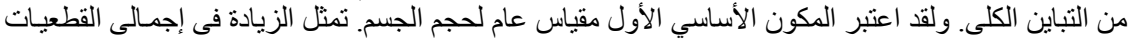

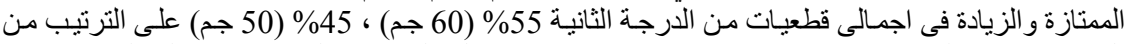

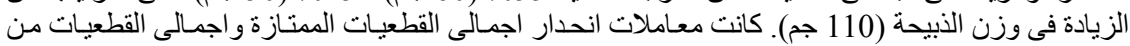

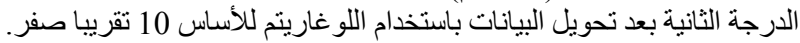

